\title{
Development and Modelling of a Lab Scaled PEM Fuel Cell Drive System for City Driving Application
}

\author{
Wei Wu \\ Faculty of Engineering \\ University College London \\ w.wu.11@ucl.ac.uk
}

\author{
Julius Partridge \\ Faculty of Engineering \\ University College London \\ julius.partridge.09@ucl.ac.uk
}

\author{
Richard Bucknall \\ Faculty of Engineering \\ University College London \\ r.bucknall@ucl.ac.uk
}

\begin{abstract}
This paper details a study carried out by UCL to explore potential improvements to the Fuel Cell (FC) bus propulsion system specifically designed for the city driving environment. In this paper, a 1:10 scaled lab based FC bus drive train has been developed to study the performance of a FC directly driving an AC induction motor. The PEMFC is the main power source for the drive train while a boost converter will work as the power conditioning system to control the FC output voltage. The AC motor will work as the bus prime mover. The system has been built in the Electrical Laboratory to evaluate the performance of a FC driving a motor. MATLAB Simulink has been used to simulate the system and has been validated against the lab based system. A number of tests have been carried out in terms of efficiency and transit change response with both the lab and simulated models. The results showed that the FC is capable of directly powering the motor in general bus driving conditions, but it is not well suited for quick transient changes. This study provides an important contribution to further improve the FC bus with hybrid propulsion systems and validates the computer model to allow faster analysis of proposed system improvements. The next step of this study is to use an energy storage system to aid the FC to cover quick transient power demand and validate it against a representative load system.
\end{abstract}

Index Terms-PEM Fuel Cell, DC/DC Converter, Induction Motor, Hybrid Propulsion, MATLAB Simulink, SuperCapacitor

\section{TRANSPORTATION BACKGROUND}

Air pollution, as one of the main causes for global warming and urban public health threats, has been raised as a global priority issue. The EU has restricted rules on air pollution controls and Britain has been struggling to meet EU air quality limits. Britain failed to meet the EU limits in 2010 and has admitted that London cannot achieve this limit until 2025 (European Commission 2015). The city of London has some of the worst air quality in the UK. The British Department for Environment Food \& Affairs air quality assessment 2013 [1] shows that the London area has exceeded UK limit levels for Nitrogen Dioxide $\left(\mathrm{NO}_{2}\right)$, Particulate matter $2.5\left(\mathrm{PM}_{2.5}\right)$, and Carbon dioxide $\left(\mathrm{CO}_{2}\right)$. In addition $\mathrm{NO}$ emissions hold the worst performance where they exceed the EU standard by $50 \%$ in some parts of London. The Transport for London (TfL) transport emissions roadmap report 2014 [2] indicates that London's transport is a key contributor for several emission types. $21 \%$ of $\mathrm{CO}_{2}$ emissions, $63 \%$ of NOx emissions and $52 \%$ of $\mathrm{PM}_{10}$ emissions are from transport in London due to the large scale of transportation demand. This paper will discuss the role that PEM Fuel Cells (FC) could play in resolving the city transportation emissions issues.

\section{Fuel Cell Bus Projects}

FCs are a clean energy source with the main benefits of zero harmful emissions and high efficiency. There are a number of hydrogen FC bus projects across European cities. CHIC (Clean $\mathrm{H}_{2}$ in European Cities Project) is a project initialised by the EU, leading the full market commercialisation of FC hydrogen powered buses and the High VLO project aims at accelerating the integration of the new generation of FC buses through increased energy efficiency and reduced ownership cost. The projects involve $48 \mathrm{FC}$ buses operating in nine European cities to demonstrate the technical and operational quality. Figure 1 provides some of the main FC bus activity across Europe under different projects.

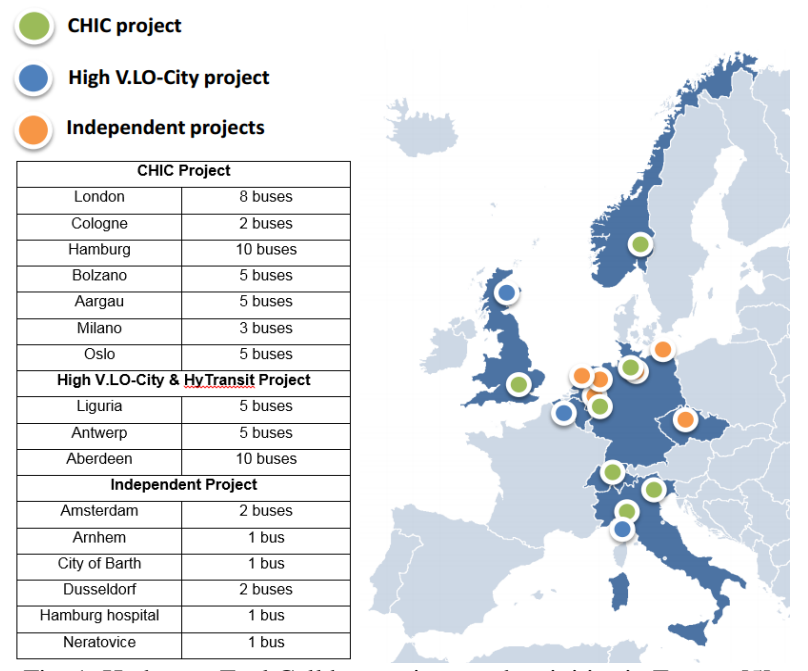

Fig. 1. Hydrogen Fuel Cell bus projects and activities in Europe [5]

London has been playing a leading role in innovative clean energy development. Following the CHIC project, London has deployed a fleet of Hydrogen Buses operating in central London and managed by TFL. In 2007-2009, the CHIC project launched five trial Hydrogen buses across major cities in Europe. Following the promising results from these trial buses, TfL announced the first FC bus fleet covering a complete route, $\mathrm{RV} 1$, in the UK. Route RV1 was operated with three trial FC buses between 2004 and 2007 but the bus could only be operated in the morning due to poor durability and reliability during that initial period. The new fleet of eight FC buses have been redesigned and provide much greater durability and reliability. There are currently eight Hydrogen buses fully covering route $\mathrm{RV} 1$ which is $9.7 \mathrm{~km}$ long in Zone 1 of London. From the customer feedback, the only difference between RV1 
FC buses and conventional buses is that the former have reduced noise and vibration [3]. The operation of the RV1 fleet has shown the technology can meet urban driving conditions and provide reasonably good performance. The UK has recently launched another FC bus fleet in Aberdeen (2015), which is jointly funded by both the High Vio City and the HyTransit projects. Public acceptance of FC buses shows a promising future of FC buses to provide a Zero emissions city zone [4]. However, the expensive capital cost of FC buses is still the main barrier for system commercialisation.

\section{PEM Fuel Cell As An Automotive Power Source}

FCs have been used in a wide range of applications which can be categorised into two areas: portable power (automobiles, backup power, military etc.) and stationary power (power station, aerospace etc.). This paper will only consider the application for automobiles where the Proton Exchange Membrane (PEM) FC stands out due to their short start-up time and low operation temperature requirement [6]. The FC is a clean and efficient power unit that has undergone substantial development in recent times and is now commercially available, offering a clean power source for transportation. FCs benefit from high efficiency, zero emissions, simplicity, flexible modular construction, low noise, small size and low weight; but they also have the disadvantages of high cost, low reliability and slow response rates. Ehsani (2010) provides a detailed characteristic comparison between some of the most commonly used power sources for transportation, which are summarised in figure 2 [7]. As figure 2 shows, FCs have high energy densities which means they can store a lot of energy but their low power density shows they are not capable of fast charge/discharge. ICEs (internal combustion engine) have both high power and energy density but the need is to replace them owing to their harmful emissions and environmental impact.

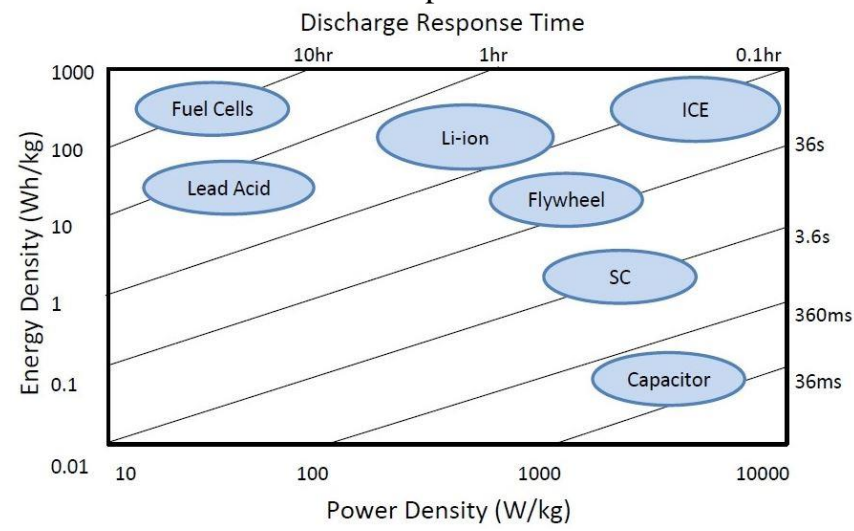

Fig. 2. Ragone plot of common energy storage devices

The UCL Electrical Laboratory has carried out a series of experiments to investigate how PEM FCs can be applied to transportation applications more effectively. Figure 3 shows an 8.5kW, 20-40V, 380A HyPM PEM FC from Hydrogenics installed in the Electrical Laboratory. The FC has been loaded with a set of switch controlled parallel connected resistive loads to simulate zero load $(0 \mathrm{~kW})$ to full load $(8.5 \mathrm{~kW})$. The FC responds directly to the load demand, therefore the output power can be controlled by changing the resistive load. The first step was to investigate how the FC efficiency changes with power and load.

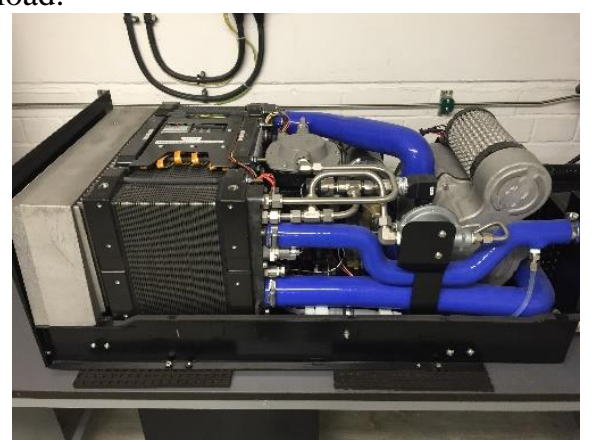

Fig. 3. 8.5kW PEM Fuel Cell test platform

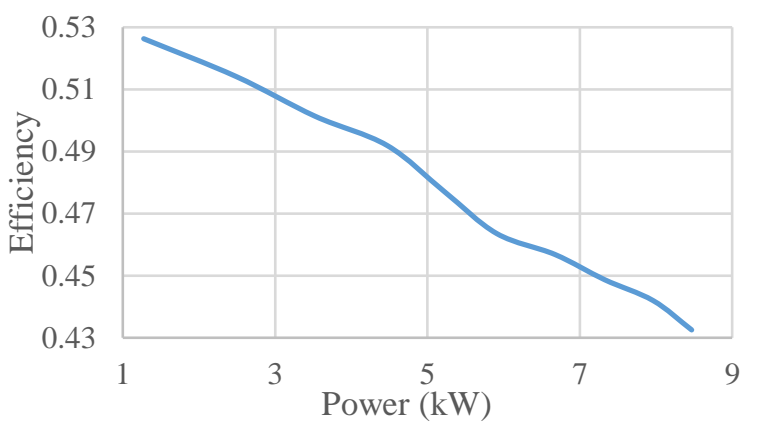

Fig. 4. HyPM PEM FC efficiency against power curve

Figure 4 shows that the PEM FC efficiency reduces as power increases which differ from a typical diesel engine's parabolic efficiency curve. This characteristic indicates that FCs perform better under lower load conditions which could be a benefit in city driving environments. The output from the FC can be directly used to propel a bus via an electric motor. The next step was to replace the resistive load with a basic drive train consisting of a boost converter, a bi-directional inverter and an induction machine.

\section{Fuel Cell Lab ScAled Drive Train}

The FC's basic drive train is a lab scaled model that has been modelled with a MATLAB Simulink computer simulation. The purpose of this drive train is to examine the FC performance when directly driving an electric motor, which is the case when a FC bus is operating. A block diagram of the basic drive train is shown in figure 5. The FC will work as the main power source of this system and is the HyPM PEM FC tested previously. The boost converter will be the power conditioning system for the FC. The Bi-inverter will converter $\mathrm{DC}$ into $\mathrm{AC}$ for the AC motor, which will work as the drive for the system.

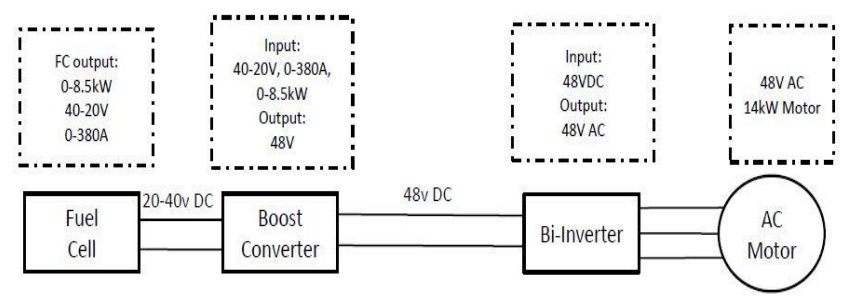

Fig. 5. FC lab scaled basic drive train block diagram 
As the FC output voltage varies with load change, a boost converter is used to keep the voltage constant. The boost converter has two main functions: using PWM control to convert the FC output voltage $(20-40 \mathrm{~V})$ to a constant value $(48 \mathrm{~V})$ and using diodes to prevent any reverse current going back to the FC. This boost converter has been custom designed and installed in the lab as figure 6 shows.

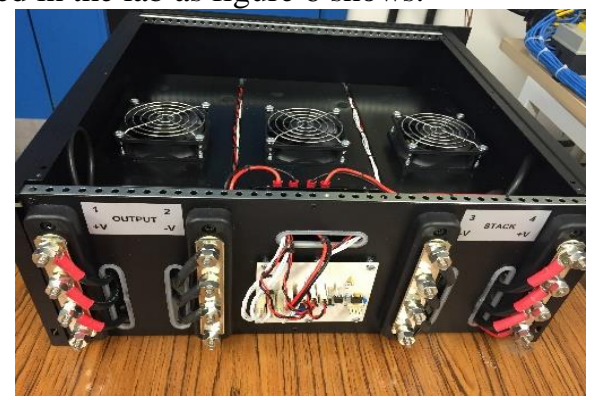

Fig. 6. Boost converter for FC and its PWM control board

The boost converter has been connected at the output side of FC and loaded with a set of resistive loads. The boost converter was then tested from $0 \%$ to $70 \%$ power (limited by resistive load power rating). The results have been plotted in figure 7 and figure 8 .

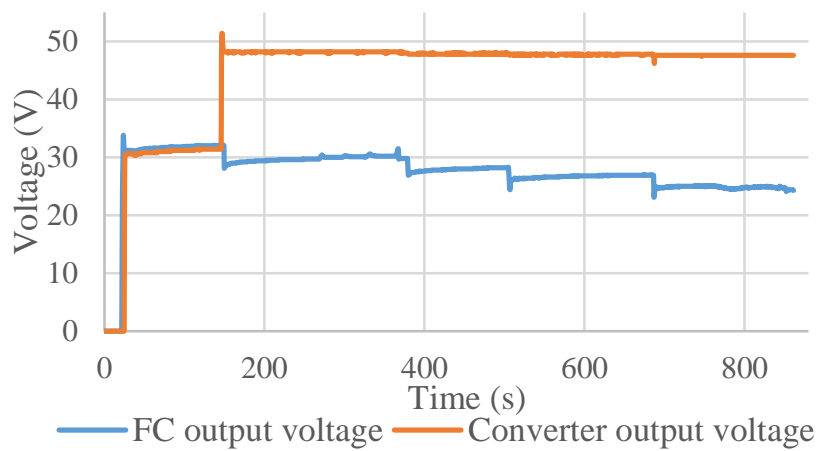

Fig. 7. Comparison between FC output voltage and boost converter voltage

As figure 7 shows, as soon as the boost converter is turned on at $\mathrm{t}=146 \mathrm{~s}$, the voltage is raised to $48 \mathrm{~V}$. The orange line indicates the voltage has been boosted to a stable $48 \mathrm{~V}$ under varying load, which would be compensated by a reduction in current. The FC output voltage (blue line) can be seen to decrease as the load increases. The input and output power have been calculated to evaluate the efficiency of the boost converter which has been plotted in figure 8 . The boost converter efficiency is approximately $90 \%$ and drops as the power increases because of the increased requirement to boost the voltage.

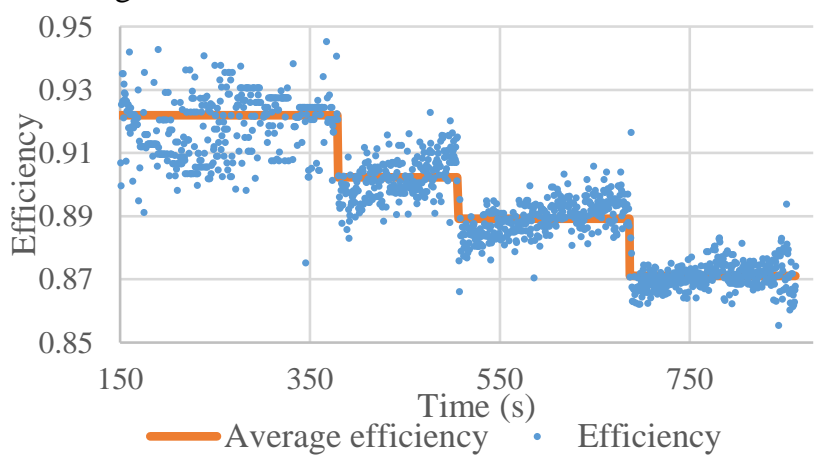

Fig. 8. Boost converter efficiency plot
The other main components of the basic drive train are the inverter and $\mathrm{AC}$ motor. The inverter and $\mathrm{AC}$ motor have been designed and installed with the inverter also working as the motor controller as figure 9 shows.

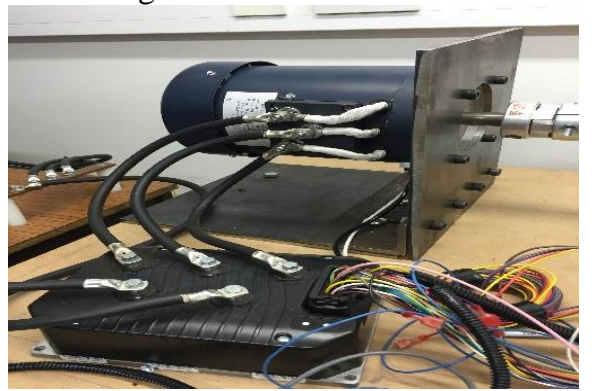

Fig. 9. Inverter (motor controller) and $14 \mathrm{~kW} \mathrm{AC} \mathrm{motor}$

The 48Vdc output from the boost converter will be supplied to the inverter (motor controller) and converted to an AC voltage supply for the induction machine. The motor has been tested using the $\mathrm{FC} / \mathrm{boost}$ converter output directly driving the machine under no load. Nominal power output from the FC has been observed when directly driving the motor because there is no load. To simulate loaded driving condition, a load system needs to be developed. A motor/generator set is under construction to apply a load on the motor and to simulate the required load conditions. With the motor/generator set, the drive motor can be used to power another identical load motor, which will work as a generator. The generated power will be dissipated with relay controlled resistive loads. The development of the load system has been completed and the relay control module has been ordered and is awaiting delivery. Loaded motor tests can only be carried out once this component has been installed and calibration of the system has been completed.

\section{FUel CEll Basic Drive Train Simulation}

While the lab building work is continuing, the same drive train system is being simulated in MATLAB Simulink. The simulated model has been validated against the lab model with the aim of allowing faster system simulation and optimisation. Two different simulation approaches have been taken to simulate this system for comparison and evaluation.

The first approach was to use the lab results to calculate a transfer function between the external load (resistive load) and internal resistance (activation loss, concentration loss and ohmic loss). The simplified equivalent circuit of this approach is shown in figure 10 . The boost converter has been simulated with a typical boost converter configuration with the parameters sized by the lab designed boost converter as shown in figure 11.

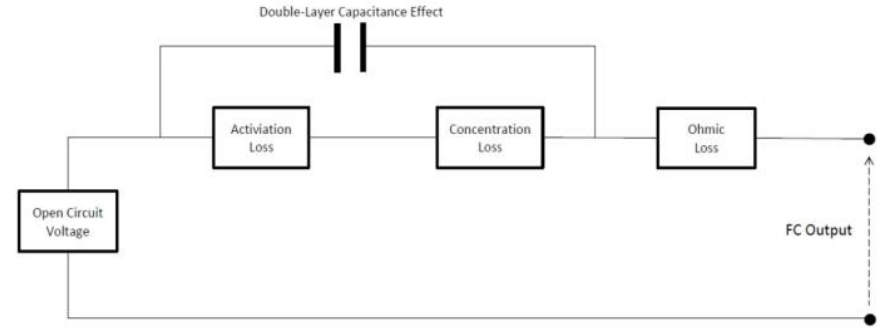

Fig. 10. Block diagram of the simplified FC electrical model for simulation 


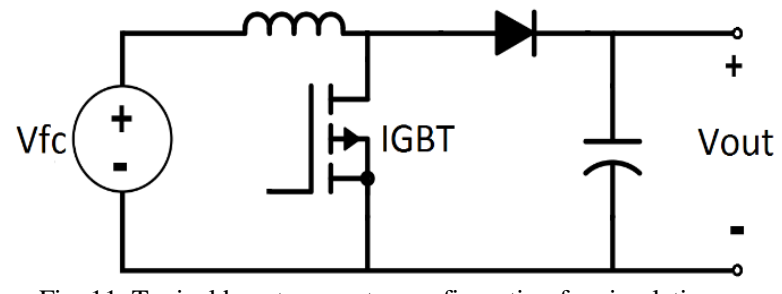

Fig. 11. Typical boost converter configuration for simulation

The second approach was to use the generic hydrogen fuel cell model in Simulink. The specifications of the HyPM have been used for this generic model for FC simulation. The boost converter has used the same typical boost converter configuration but in a different Simulink library. Therefore two simulation models have been developed for the FC simulation in two different component libraries (Simscape and SimPower Systems).

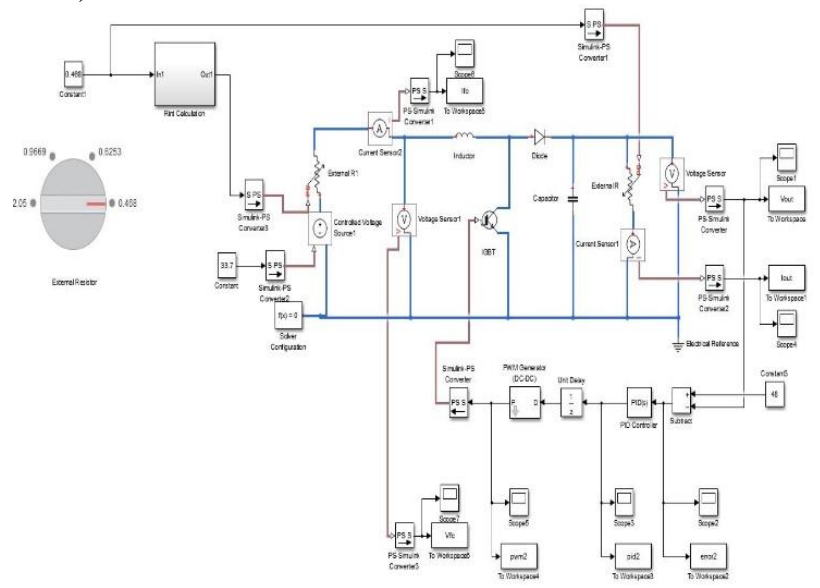

Fig. 12. FC/boost converter simulation with transfer function method

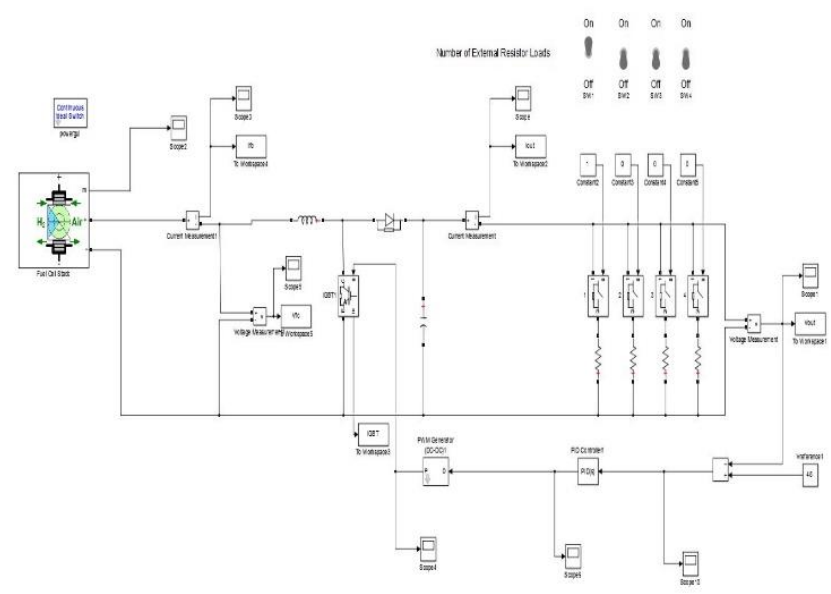

Fig. 13. FC/boost converter simulation with generic model method

Figure 12 and figure 13 show both the Simulink models developed to carry out the simulations. For Comparison the load for each model uses the same resistive loads as used in the lab system. The first simulation results are for the FC simulation under the same load configuration as the lab based model, with the results shown in figure 14.

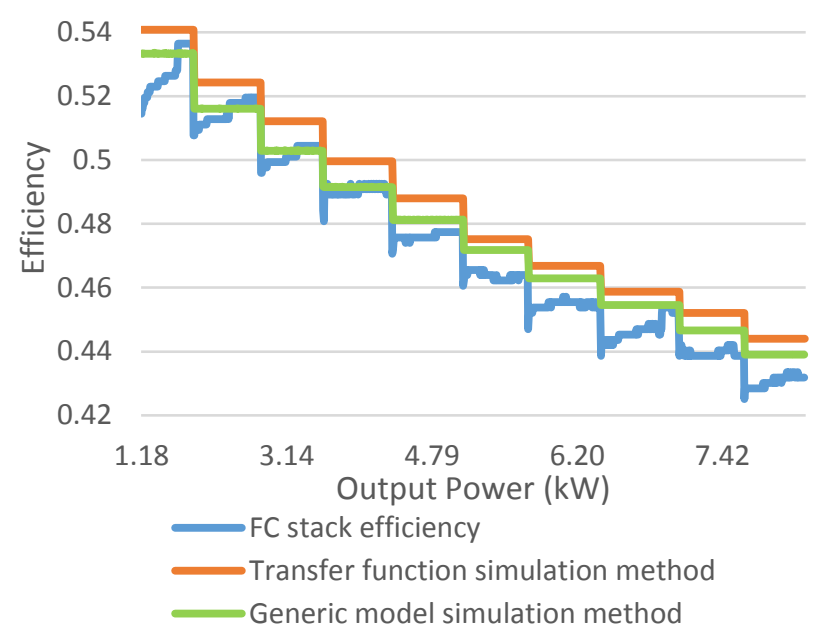

Fig. 14. FC power-efficiency plot between lab and simulation

As figure 14 shows, both simulation approaches show similar results and are both slightly higher than the actual lab result (blue line). An interesting trend from the lab model result has been observed which could explain the reason why the simulated results are slightly higher than the lab result. After each step change, the efficiency of blue line tends to increase with time. The reason may be that since the PEM FC attains optimum efficiency around $60^{\circ} \mathrm{C}$, the $\mathrm{FC}$ needs time to reach this optimum operating temperature. The simulated model ignores temperature effect on efficiency, which explains why lab results are slightly lower than those for the simulations.

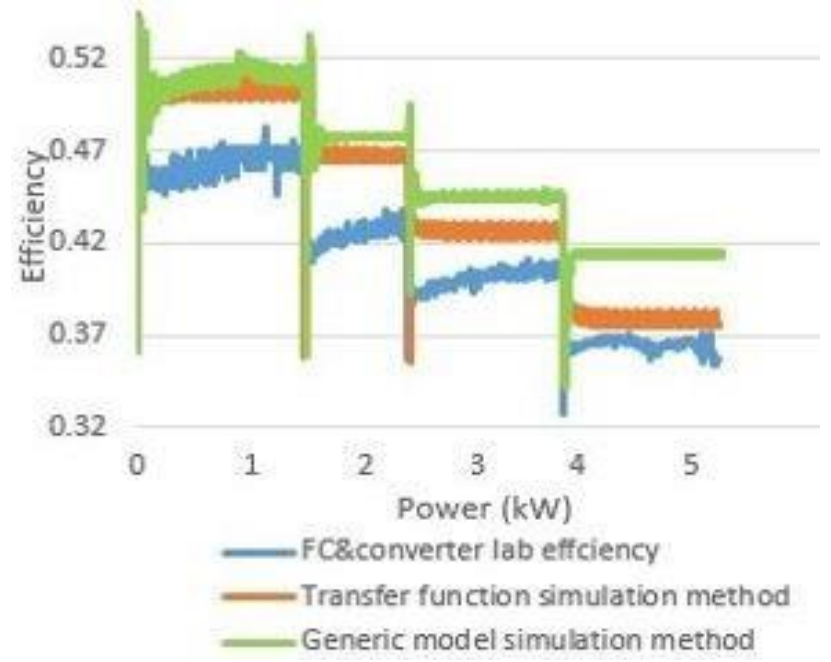

Fig. 15. FC\&converter power-efficiency plot between lab and simulation

Figure 15 shows the plot of the overall efficiency of both the FC and boost converter working together. Again, both models have slightly higher efficiencies, which could be a result of the temperature effect identified earlier. As the power output increases, the efficiency from the transfer function method approaches that for the lab results while for the generic model method efficiency remains higher. The motor and its controller have also been simulated but not validated because the lab model is not yet completed. Thus far it is difficult to determine which simulation method provides better accuracy, therefore simulations will continue to be carried out using both methodologies. Since the motor load is still under construction, 
the motor simulation results will not be included in this paper, as they are not yet validated. However the drive train with just the FC and boost converter can be tested under varying loads to determine response rates of the FC.

\section{FuEl CELl UNDER VARYING LOAD}

The FC basic drive train has been built and validated in both lab and simulation models with the exception of motor load. This model can be used to test the performance of the FC under city driving conditions. Constant start and stop occurs in a typical city bus driving cycle, which requires continuous changes in the power demand. It is important to investigate how the FC responds to sudden changes in the power demand, which would occur frequently in a typical city driving cycle. A set of tests have been carried out to determine the response of the developed FC drive train under resistive load when the power demand step increases from: 0-25\%, 0-50\%, 0-75\% and $0-100 \%$. The two most important parameters under varying load are the hydrogen flow rate response and power change and are shown in figures 16 and 17.

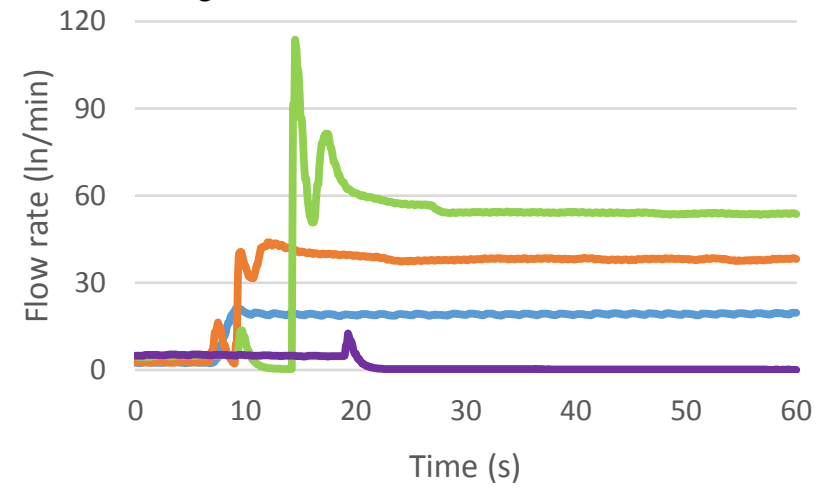

Flow rate from 0-25\% load Flow rate from 0-50\% load

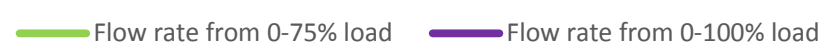

Fig. 16. FC hydrogen flow rate response with power change

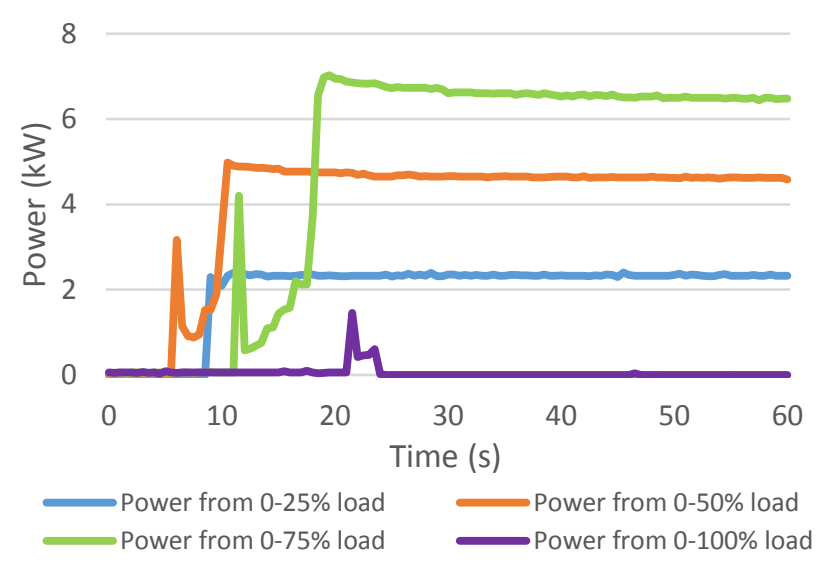

Fig. 17. FC output power response with power change

- Load 0-25\% (blue): Hydrogen flow rate takes approximately $3 \mathrm{~s}$ to adjust and a small overshot has been observed. The stack power responds to the load change reasonably quickly and becomes stable at $2.3 \mathrm{~kW}$.
- Load 0-50\% (orange): Hydrogen flow rate takes approximately $8 \mathrm{~s}$ to become stable at the required flow rate, two hydrogen drops and a small overshot have been observed. The FC stack also has a power drop, which is caused by hydrogen drop and then increases to $5 \mathrm{~kW}$ output power. Then the FC power takes roughly another $15 \mathrm{~s}$ to drop from the slight overshoot $(5 \mathrm{~kW})$ to the stable power output $(4.6 \mathrm{~kW})$.

- Load 0-75\% (green): Hydrogen flow rate takes approximately 20 s to become stable and a big spike along with harmonics have been observed. The FC stack power also has a power drop and then rises to the required power. During this process, the HyPM FC reported 'Blower Low Voltage Alarm' and 'Hard Recovery Alarm' but recovered to produce power. The blower low voltage alarm has been defined as the FC voltage reaching a lower threshold. The hard recovery alarm has been defined as a transitional state when the stack becomes unstable during running and the ECU (engine control unit) has attempted to recover the stack.

- Load 0-100\% (purple): The hydrogen flow rate and stack power attempt to increase but failed and both drop to zero. HyPM reported 'Cell Low Voltage Alarm' and 'Hard Recovery Alarm' and tripped.

It can be seem from the results that the FC struggles to respond quickly and even failed to reach the required power when large changes in the power demand were required quickly. There are two main reasons for the slow response of the FC: one is the small power density of the FC, as seen in figure 2; the other is that hydrogen fuel flow is controlled by mechanical parts such as valves and pipeworks which can be slow to adjust. These results indicate that the FC is not capable of meeting large step changes in the power demand; therefore the FC alone is not well suited to the city driving environment where quick and regular changes to the power demand occur. In addition this would not allow for regenerative braking which significantly decreases the overall efficiency of the system and reverse current could potentially damage the FC. As such the FC could be used as part of a hybrid system, making use of some form of energy storage to overcome the varying power demand issue.

\section{DISCUSSION ON FUEL CELL HYBRID SYSTEM}

Hybrid propulsion systems use two or more distinct types of power sources. There are 1600 hybrid buses operating in London, which is $20 \%$ of the total London bus fleet. The diesel electric hybrid buses have shown promising performance in both power efficiency and emission control, however they still rely on a diesel engine and as a result produce harmful emissions [8]. Applying a hybrid propulsion system with FC technology will have additional benefits and can be summarised into five points.

1) Enable regenerative brake: The electric motor can work as a generator to charge an energy storage system, which greatly reduces the energy lost in conventional braking. 
2) Covering transient demand: Energy storage with high power density can be used to manage transient power demand and overcome the FC time response issue.

3) FC downsizing: The inclusion of an energy storage system has the additional advantage that the FC can be decreased in size as it will not be required to meet the high transient demands by itself which could reduce the expensive FC stack cost.

4) Efficiency optimisation: The FC can be kept near constant optimised efficiency under low load while the energy storage can supplement transient power demand or absorb excess power from either the FC or from regenerative braking.

5) Idle off: While the bus is idling, all of the FC output can be used to charge the energy storage through a DC/DC converter, which would prevent engine idle losses.

The most commonly used forms of energy storage in hybrid buses are Li-ion batteries and supercapacitors due to their high power density characteristics as can be seen from figure 2 and are mature technologies [7] [9]. The combination of high energy density FC and high power density energy storage can potentially provide a future zero emission bus system with a higher efficiency and lower the cost than for buses with FCs alone.

\section{FUTURE WORK}

This study has developed a basic FC drive train in both a lab model and simulated models. The FC and boost converter have been tested and provide good efficiency curves, which have also been validated with the computer models. The drive train has been tested under varying load under rapid power demand changes. The results have indicated that the FC can provide a zero emission bus solution but it is unable to cover large transient power changes. The FC could be potentially damaged in the worst-case scenario where the FC power demand increases rapidly. Therefore energy storage has been proposed for the FC bus system to overcome this large power demand requirement as well as to increase the overall efficiency and potentially reduce the costs.

The next stage in the drive train development is to add an energy storage system for overall hybrid system efficiency evaluation and to design a motor load system for a more realistic testing platform. The energy storage and load system have been designed to a block diagram level. The energy storage can be sized by balancing between motor power demand and FC output power. In addition the size of the energy storage system can be optimised by studying the power demand of specific driving cycles and to determine the optimal power balance between the FC and the energy storage. A buck/boost converter is also required to control the voltage during charge and discharge of the energy storage system. It can also work as an energy storage controller to control the charge and discharge.

The load system has also been proposed with a solution to create a motor/generator set. An identical motor will be coupled to the drive motor. And the second motor can either work as a generator to dissipate power through a resistor bank or work as a motor to be driven by a battery pack to apply a positive torque. The resistor bank and battery pack will be controlled by a logic controller. Last but not least is to add a flywheel unit to represent the bus inertia between the two motors. The completed FC hybrid drive train design has been shown in figure 18.

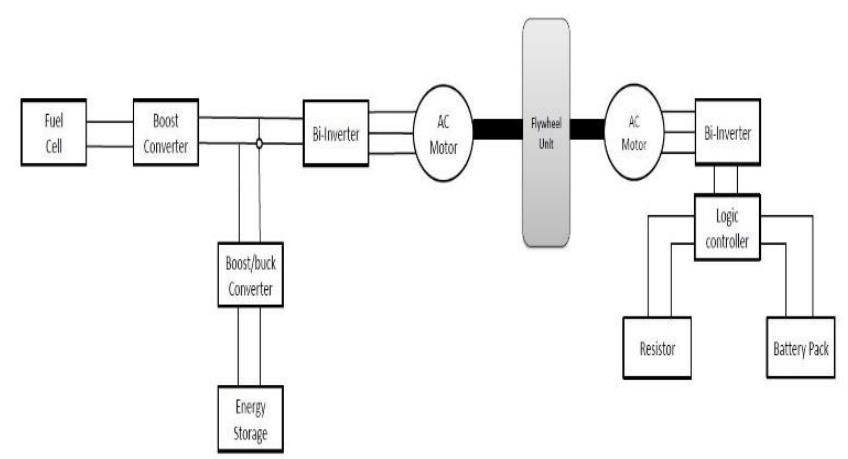

Fig. 18. Block diagram of the complete FC hybrid drive train

The completed drive train will also be simulated in Simulink and validated against the lab model. This system can then be used to optimise the efficiency of the FC electric hybrid propulsion system. The outcome of this work will be both a lab and Simulink model of a scaled FC/energy storage hybrid bus system with the overall goal of optimising the system for operation under city driving conditions.

\section{ACKNOWLEDGEMENTS}

This material is based on work supported by the Engineering and Physical Sciences Research Council (EPSRC), HyFCap Project under grant E0/K021192/1.

\section{REFERENCES}

[1]. T Bush, S Eaton, S Gray, C Jephcote, A Kent, A Loader. 'Air pollution in the UK 2013', Department for environment food \& rural affairs, pp 30-38, 2013

[2]. Transport for London. 'Transport emission roadmap, cleaner transport for a cleaner London', Mayor of London, pp 7-10, 2014

[3]. D Raine. 'Bringing hydrogen to London's streets', Air products \& TFL, 2009

[4]. E Watt, 'The Aberdeen hydrogen bus project', Aberdeen city council, 2015

[5]. Element energy limited. 'Post-2014 London hydrogen activity: options assessment', TFL \& London Hydrogen partnership, 2012

[6]. F Barbir, 2005, PEM Fuel Cells Theory and Practice. Elsevier Academic Press, P7, P11, P24, P45

[7]. M Ehsani, Y Gao, A Emadi, 2010, Modern Electric, Hybrid Electric and Fuel Cell Vehicles. CRC Press, P108,P218, P322

[8]. Transport for London, 2015, 'London Buses Emissions Reduction', Finn Coyle, Mayor of London

[9]. I Husain, 2011, Electric and hybrid vehicles design fundamentals, Second edition, CRC Press, P226,P261, P288, P440 